\title{
Research on Chloride Penetration Resistance of Phosphoaluminate Cement Concrete
}

\author{
Wu-Jian Long, Ning Xu Han, Da Wang Li, Feng Xing, and Ya-Man Zhao \\ Guangdong Provincial Key Laboratory of Durability for Marine Civil Engineering, Shenzhen Durability Center \\ for Civil Engineering, College of Civil Engineering, Shenzhen University
}

\begin{abstract}
The chloride penetration resistance of phosphoaluminate cement (PAC) concrete was investigated in this study. The effects of mixture proportioning parameters, including cement content, water-cement ratio (w/c), and superplasticizer content on chloride ion penetration resistance of PAC concrete were investigated by the rapid chloride migration test (RCM). The result shows that the increase of cement content and the decrease of w/c can reduce the coefficient of chloride ion penetration of PAC concrete at a certain range. Moreover, the penetration of chloride ion can be declined effectively when polycarboxylate superplasticizer is employed. The PAC concrete exhibited better chloride penetration resistance compared with normal Portland cement (PC) concrete prepared with the same mixture proportioning parameters. This is due to the fact that the hydration mechanism and the hydration products of PAC concrete are different from that of PC concrete.
\end{abstract}

Keywords: phosphoaluminate cement, cement content, chloride penetration, mix proportion parameter.

\section{INTRODUCTION}

In recent years, the service life and durability of civil works in coastal corrosive environment have been key concerns for all governments as well as researchers around the world. It is known to all that the chloride corrosion of steel bars may lead to a serious problem on durability of coastal and marine reinforced concrete structures. At present, corrosion damage due to chloride penetration of the reinforced concrete has become one of the major reasons for reinforced concrete structure deterioration. According to the statistics, the loss due to corrosion damage to the concrete structures caused by the chlorides in the environment has made up $2-4 \%$ of the national gross product in some coastal countries in the world (Boddy, Hooton, \& Grube, 2001; Dhir \& Jones, 1990; Guo, Qin, \& Sun, 2010).

Compared with the current most universally used Portland cement concrete, PAC concrete is a relatively new system. In the previous investigations, the researchers' focus is concentrated on the preliminary research, including mineral phase synthesis, cement hydration process, the influence of the admixtures on setting time, the durability of cement paste, mortar, and the early physicochemical properties (mechanical property, water resistance, and the rheological properties of paste), an so on (Harold, 1995; Jiashan, Agrawal, \& Roy, 1998; Li, Hu, \& Liu, 1999; Polder, 1995; Prezzi \& Geyskens, 1996; Ren, Zhang, \& Li, 2007). However, research on concrete behavior and material properties based on phosphoaluminate cementing materials, especially systematic research on the durability of PAC concrete, has rarely been reported, and never has research on the use of such concrete in the coastal environment been reported. Systematic research on the chloride penetration resistance of such concrete will facilitate solving the problem of durability of the concrete structures in the severe environment regions caused by chloride corrosion, and extend the service life of the concrete structures.

Although many factors may affect the performance of chloride penetration resistance, especially under the condition that chemical and mineral admixtures are universally applied to modern concrete, other factors, for example, early strength agent, air entraining agent, water reducer, slag, and fly ash, all may obviously influence the coefficient of chloride penetration in the concrete (Steinke \& Roy, 1991; Wang \& Li, 2012). However, research on the performance of chloride penetration resistance of PAC concrete is still at the initial stage, and therefore in this research, only some major factors among numbers of influential factors, that is, the influence of cement content, water-cement ratio, and polycarboxylate superplasticizer are considered.

\section{EXPERIMENT}

\subsection{Materials}

Cement: made in lab, production procedures are as follows: mix the raw materials containing aluminum $(A)$, phosphorus $(P)$, and calcium $(C)$ evenly in a certain 
proportion; burn them in the high temperature furnace

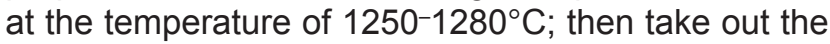
clinkers and fast cool; then, grind the well-burnt cement clinkers into preset fineness. Fine aggregate: river sands, fineness modulus 3.1 , bulk density $1540 \mathrm{~kg} / \mathrm{m}^{3}$, and tapped density $1720 \mathrm{~kg} / \mathrm{m}^{3}$; Coarse aggregate: granites, 5-31.5 continuous grading, bulk density $1470 \mathrm{~kg} / \mathrm{m}^{3}$, and tapped density $1590 \mathrm{~kg} / \mathrm{m}^{3}$; Water reducer: Sika $\AA$ ViscoCrete 3301 polycarboxylate superplasticizer.

\subsection{Test methods}

At present, the universal methods to test the performance of chloride penetration resistance of concrete are mainly electric field methods, including electric flux method and rapid chloride migration (RCM method). However, electric flux method has not been recognized by the majority of researchers, and it is believed that such a test result overstates admixtures' chloride penetration resistance of concrete; moreover, this method conflicts with the universally accepted extraction method (Wee, Suryavanshi, \& Tin, 2000; Wu \& Wu, 2011; Xing, Yi, \& Li, 2009; Yi, Guo, \& Cheng, 2007), while RCM method and extraction method can mutually prove each other; therefore, in this research, RCM method is adopted to test chloride penetration resistance. A cylinder with the diameter of $100 \pm 1 \mathrm{~mm}$ and height $50 \pm 1 \mathrm{~mm}$ is used as the test piece.

The nonstationary chloride migration coefficient of concrete is calculated in accordance with Eq. (1):

$$
\begin{aligned}
D_{\mathrm{RCM}}= & \frac{0.0239 \times(273+T) L}{(U-2) t} \\
& \left(X_{\mathrm{d}}-0.0238 \sqrt{\frac{(273+T) L X_{\mathrm{d}}}{U-2}}\right)
\end{aligned}
$$

Where $D_{\mathrm{RCM}}$-the nonstationary chloride migration coefficient of concrete, with the precision of $0.1 \times 10^{-12} \mathrm{~m}^{2} / \mathrm{s}$; U-the absolute value of the voltage used in this experiment (V); $T$-the average value of initial and end temperature of the anode solution $\left({ }^{\circ} \mathrm{C}\right) ; \mathrm{L}$ - the thickness of the test piece $(\mathrm{mm})$, with the precision of $0.1 \mathrm{~mm}$; and $X_{\mathrm{d}}$-the average value of chloride penetration depth $(\mathrm{mm})$, with the precision of $0.1 \mathrm{~mm}$; $t$-test duration (h).

\subsection{Mix proportion}

Based on the preliminary mix design, it is found that with the cement content less than $350 \mathrm{~kg} / \mathrm{m}^{3}$, the binders cannot well pack the coarse aggregate, therefore, in this test, the cement content of 400$500 \mathrm{~kg} / \mathrm{m}^{3}$ is chosen. The Portland cement employed in this test is common PO 52.5 cement. The mix proportion of PAC concrete used in this test is shown in Table 1.
Table 1. Mixture Proportioning of PAC Concrete.

\begin{tabular}{cccccc}
\hline $\begin{array}{c}\text { Mix. } \\
\text { no }\end{array}$ & w/c & $\begin{array}{c}\text { Cement } \\
\mathbf{k g} / \mathbf{m}^{3}\end{array}$ & $\begin{array}{c}\text { Sand } \\
\mathbf{k g} / \mathbf{m}^{3}\end{array}$ & $\begin{array}{c}\text { Coarse } \\
\text { aggregate } \\
\mathbf{k g} / \mathbf{m}^{3}\end{array}$ & $\begin{array}{c}\text { Super- } \\
\text { plasticizer } \\
\% \text { cement } \\
\text { content }\end{array}$ \\
\hline PAC1 & 0.33 & 400 & 793 & 1141 & 0.66 \\
PAC2 & 0.33 & 400 & 639 & 1297 & 0.33 \\
PAC3 & 0.38 & 400 & 622 & 1261 & 0.66 \\
PAC4 & 0.38 & 400 & 770 & 1110 & 0.33 \\
PAC5 & 0.33 & 500 & 582 & 1179 & 0.66 \\
PAC6 & 0.33 & 500 & 720 & 1038 & 0.33 \\
PAC7 & 0.38 & 500 & 694 & 997 & 0.66 \\
PAC8 & 0.38 & 500 & 559 & 1134 & 0.33 \\
\hline
\end{tabular}

\subsection{Sampling and curing}

The test specimens with the diameter of $100 \mathrm{~mm}$ and height of $100 \mathrm{~mm}$ were prepared. The specimens were placed in the standard curing room and demolded at $24 \mathrm{~h}$. The samples were continuously placed in the curing room 1 week before the test period, then a cylinder with the height of $50 \pm 2 \mathrm{~mm}$ was cut off from the middle of the test piece and used as the test specimen in the test. It is important to note that the side that is close to the concrete casting surface should be exposed to the side of the chloride solution.

\section{TEST RESULTS AND DISCUSSIONS}

The test results of chloride penetration resistance of PAC concrete can be found in Table 2. The 28-day chloride diffusion coefficient of PAC concrete ranges from $3.6 \times 10^{-12}$ to $5.2 \times 10^{-12} \mathrm{~m}^{2} / \mathrm{s}$. It can be found that the chloride penetration resistance varies significantly with the change of the mix proportions of the PAC concrete. At the age of 56 days, the diffusion coefficients decrease at different degrees (from 14 to 53\%), as shown in Figure 1. Although the development of compressive strength of PAC concrete becomes slowly after 28 days, the curing time has an obvious effect on the chloride penetration resistance.

Table 2. Chloride diffusion coefficient from RCM test $D_{\mathrm{RCM}}\left(\times 10^{-12} \mathrm{~m}^{2} / \mathrm{s}\right)$.

\begin{tabular}{ccccc}
\hline Mix. no & PAC1 & PAC2 & PAC3 & PAC4 \\
\hline 28 & 4.3 & 3.6 & 5.9 & 4.2 \\
56 & 3.7 & 2.8 & 4.7 & 4.1 \\
\hline Mix. no & PAC5 & PAC6 & PAC7 & PAC8 \\
\hline 28 & 3 & 5 & 5.2 & 5.2 \\
56 & 1.4 & 4.2 & 4.3 & 3.9 \\
\hline
\end{tabular}

The concrete pore structure and its binding ability to chloride are two important factors that can influence its chloride penetration resistance performance; therefore, the test mainly starts with these two factors. 


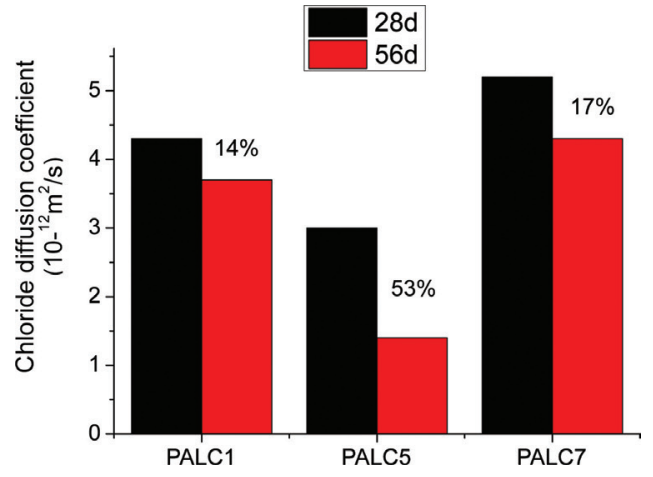

Figure 1. Effect of elapsed time on the chloride penetration resistance.

\subsection{Effect of cement content on the chloride penetration resistance}

By analyzing the test data, it can be found that when other factors are all the same, the chloride diffusion coefficients of PAC1 with the cement content of $400 \mathrm{~kg} /$ $\mathrm{m}^{3}$ at 28 and 56 days are, respectively, 30 and $62 \%$ higher than those of PAC5 with the cement content of $500 \mathrm{~kg} / \mathrm{m}^{3}$, as shown in Figure 2a; the chloride diffusion coefficients of PAC3 with the cement content of $400 \mathrm{~kg} / \mathrm{m}^{3}$ at 28 and 56 days are, respectively, 13 and $9 \%$ higher than those of PAC7 with the cement content of $500 \mathrm{~kg} / \mathrm{m}^{3}$, as shown in Figure $2 \mathrm{~b}$. It can be concluded that cement content has a significant effect on the chloride penetration resistance of PAC concrete.

(a)

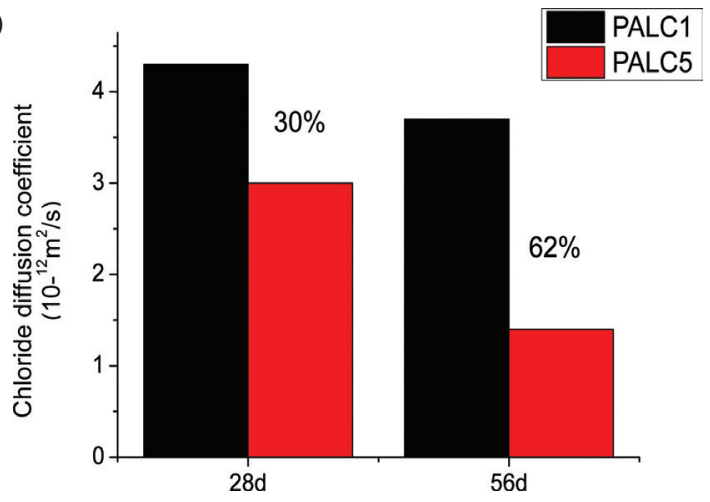

(b)

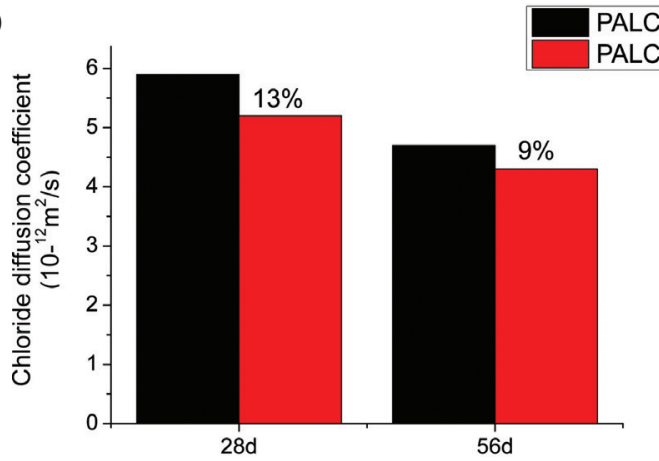

Figure 2. Effect of cement content on the chloride penetration resistance. (a) PAC1 vs. PAC5. (b) PAC3 vs. PAC7.
In the hardened concrete, the chloride penetration resistance mainly depends on the chemical binding and physical absorption to the chlorides by hydration products of the cement; the more the cement content is, the more its hydration products will be, and the more the chlorides that can be bound. Furthermore, more hydration products fill in the gaps of the concrete, and the external corrosive ions cannot penetrate into the concrete. The curing period is of vital importance for the cement hydration, but in terms of PAC, the hydration process has mostly been finished before 28 days. The 56-day strength still increases a little more than that of the 28 days strength, the 56-day chloride penetration resistance performance of PAC concrete also increases a little more than that of the 28 days strength.

\subsection{Effect of w/c on the chloride penetration resistance}

Under the condition that cement content and water reducer are the same, w/c has an obvious effect on the chloride penetration resistance of PAC concrete. The cement contents of PAC1 and PAC3 are both $400 \mathrm{~kg} / \mathrm{m}^{3}$, and the chloride diffusion coefficient of PAC1 with the w/c of 0.33 at 28 and 56 days are, respectively, 27 and $21 \%$ smaller than those of PAC3 with the w/c of 0.38 , as shown in Figure 3a; the cement contents of PAC5 and PAC7 are both $500 \mathrm{~kg} / \mathrm{m}^{3}$, and the chloride diffusion coefficient of PAC5 with the w/c of 0.33 at 28 and 56 days are, respectively, 42 and $67 \%$ smaller than those of PAC7 with the w/c of 0.38 , as shown in Figure $3 \mathrm{~b}$. It can be concluded that when the cement content is higher, w/c has a significant effect on the chloride diffusion coefficient.

(a)

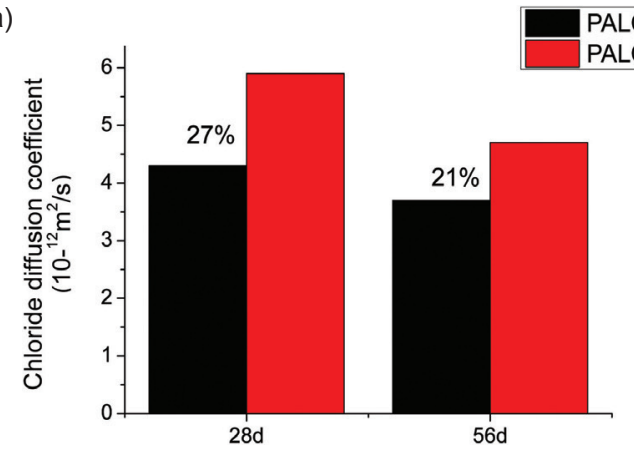

(b)

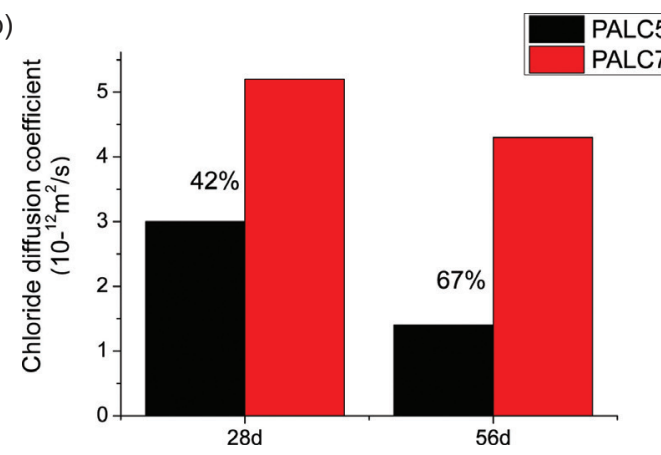

Figure 3. Effect of $w / c$ on the chloride penetration resistance. (a) PAC1 vs. PAC3. (b) PAC5 vs. PAC7. 
The smaller the $\mathrm{w} / \mathrm{c}$ is, the smaller the chloride diffusion coefficient of PAC concrete will be, which shows that its ability to resist chloride diffusion will be much stronger. The reason is that when the w/c is smaller, the pores in the hardened concrete will be less, the structure will be more dense, and it will be more difficult for the solution containing chlorides to enter into the concrete; therefore, the ability to resist chloride penetration can be improved.

\subsection{Effect of water reducer on the chloride penetration resistance}

Water reducer also has a significant effect on the chloride penetration resistance performance of PAC concrete. When cement content is $400 \mathrm{~kg} / \mathrm{m}^{3}$, the water reducer contents of PAC1 and PAC2 which are of the same w/c are, respectively, 0.66 and $0.33 \%$ of the cement contents whose chloride penetration coefficients are quite different from each other; the former 56-day chloride penetration coefficient is $24 \%$ higher than the latter one; for PAC3 and PAC4, both of whose cement contents are $400 \mathrm{~kg} / \mathrm{m}^{3}$, the w/c are the same, and water reducers are, respectively, 0.66 and $0.33 \%$, and the former one 56-day chloride diffusion coefficient is $13 \%$ higher than that of the latter one; a similar phenomenon may also be seen if the experimental results of other test pieces are analyzed. The reason is that the chloride penetration resistance performance of cement is mainly influenced by its porosity and pore diameter distribution, while the adding of water reducer may facilitate concrete spread more evenly and have much better workability, making the cement hydration more complete, and the hydration products can better fill the harmful pores inside the hardened concrete. In a word, water reducer can optimize the pore structure in the cement as well as the compactness of the concrete and make significant contributions to its chloride penetration resistance.

\subsection{Microstructure analyses of hardened cement paste}

By comparing the 28-day SEM pictures (see Figure 4) of Portland cement and PAC, it can be found that the hydration products of Portland cement are mainly cotton-like aluminate and fibrous silicate gel whose microscopic structure is of a certain compactness; the hydration products of PAC are mostly gel-like and floc-like, whose microscopic structure compactness is obviously superior to that of Portland cement. Because the hardened cement paste of the PAC is much more compact than that of the Portland cement, the PAC exhibit the excellent ability to resist chloride penetration.

According to the preliminary experimental research, it has been found that PAC has early-strength and

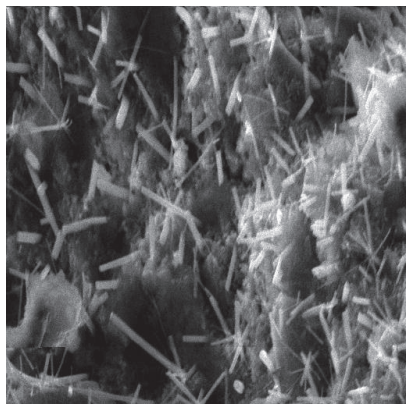

(a)

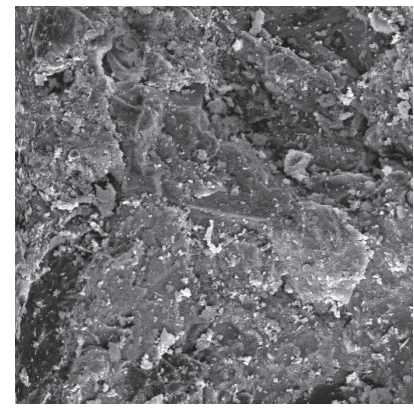

(b)
Figure 4. SEM diagrams of cement paste. (a) Portland cement. (b) PAC.

high-strength characteristics. At the early age, its hydration products may well fill in the internal pores and form a perfect three-dimensional network structure, which is mutually cross-linked. The compact microscopic structure is not easy for external chlorides to penetrate into the concrete, which is helpful in protecting the concrete reinforcement from being corroded by chloride ions.

\section{CONCLUSIONS}

According to the experiment research, conclusions can be drawn as follows:

(1) PAC concrete has excellent chloride penetration performance; curing period has an obvious influence on its chloride penetration coefficient, and 56-day chloride penetration resistance has an obvious advantage compared with that of 28 days.

(2) The cement content, w/c, and water reducer, which have key influences on the chloride penetration resistance performance of common Portland cement concrete, also play key roles in the chloride penetration resistance performance of PAC concrete; in a certain range, the chloride diffusion coefficient of PAC concrete decreases with the increase of cement content and the decrease of $\mathrm{w} / \mathrm{c}$, and polycarboxylate superplasticizer can improve the chloride diffusion resistance performance.

(3) Microstructure analysis shows that the hydration products of PAC concrete are mostly gel-like and floc-like, which may well fill in the internal pores of the hardened cement paste, forming a threedimensional network structure, which is mutually cross-linked. The dense microstructure of PAC concrete is not easy for external chlorides to penetrate, which is helpful in protecting concrete reinforcement from being corroded by chloride ions. 


\section{ACKNOWLEDGMENTS}

The authors gratefully acknowledge the financial support provided by the National Natural Science Foundation of China (No. 51278306 and 51008197), the Science Industry Trade and Information Technology Commission of Shenzhen Municipality (No. GJHZ20120614144906248 and JCYJ20120613155343592).

\section{REFERENCES}

Boddy, A., Hooton, R. D., \& Grube, K. A. (2001). Long-term testing of the chloride penetration resistance of concrete containing high-reactivity metakaolin. Cement and Concrete Research, 21(5), 759-765.

Dhir, R. K., Jones, M. R., Ahmed, H. E. H., \& Seneviratne, A. M. G. (1990). Rapid estimation of chloride diffusion in concrete. Magazine of Concrete Research, 42(152), 177-185.

Guo, W., Qin, H. G., Sun, W., \& Yang, Y. (2010). Effect of admixture and water to binder ratio on chloride ion permeability of concrete. Bulletin of the Chinese Ceramic Society, 29(6), 1478-1483. (in Chinese).

Hamid, A. A. (1995). Improving structural concrete durability in the Arabian Gulf. Concrete International, 17(7), 32-35.

Jiashan, H., Agrawal, K., \& Roy, R. (1998). Investigation of hydration phase in the system $\mathrm{CaO}-\mathrm{SiO}_{2}$ $\mathrm{P}_{2} \mathrm{O}_{5}-\mathrm{H}_{2} \mathrm{O}$. Journal of Material Research, 3(4), 772.

Li, S. Q., Hu, J. S., Liu, B., Zhang, G., Cao, W., Wang, Q., \& Zhang, N. (1999). Fundamental study on phosphoaluminate cement. Cement and Concrete Research, 29(10), 1549-1554.

Polder, R. B. (1995). Chlorie diffusion and resisting of five concrete mixes for marine environment.
RILEM international workshop on chloride penetration into concrete. Auxt-Rent-LesChevreuse, France.

Prezzi, M., \& Geyskens, P. (1996). Reliability approach to service life prediction of concrete exposed to marine environments. ACl Material Journal, 93(6), 522-544.

Ren, S. X., Zhang, G. L., Li, S. Q., Liu, B., \& Hu, J. S. (2007). Study on water-resistance of phosphoaluminate cement. Bulletin of the Chinese Ceramic Society, 26(1), 48-51, 112. (in Chinese).

Steinke, R. A., \& Roy, D. M. (1991). Development of chemically bonder ceramics in the $\mathrm{CaO}-\mathrm{SiO}_{2}-\mathrm{P}_{2} \mathrm{O}_{5}-$ $\mathrm{H}_{2} \mathrm{O}$ system. Cement and Concrete Research, 21(1), 66.

Wang, W. L., \& Li, S. Q. (2012). Study of phosphoaluminate cement slurry carbonation. Journal of Building Materials, (3), 334-338. (in Chinese).

Wee, T. H., Suryavanshi, A. K., \& Tin, S. S. (2000). Evaluation of rapid chloride permeability test (RCPT) result for concrete containing mineral admixtures. ACI Materials Journal, 97(2), 221-232.

Wu, J. H., \& Wu, Y. M. (2011). Overview of test methods of chloride ion permeability in concrete. Concrete, (2), 72-74. (in Chinese).

Xing, F., Yi, Z. H., Li, S. Q., et al. (2009). Simulated seawater-resistance of blended portlandphosphoaluminate mortar. Silicates Industrials Ceramic Science and Technology, 74(11-12), 339-342.

Yi, C., Guo, T. T., Cheng, T., et al. (2007). Experimental study on comparing between the NEL and ASTMC1202 testing method for chloride ion permeability in concrete. Concrete, 10(3), 4-6. (in Chinese). 